
\title{
$\begin{array}{ll}\text { Research Square } & \text { They should not be considered conclusive, used to inform clinical practice, } \\ \text { or referenced by the media as validated information. }\end{array}$ \\ Differential Proteomic Analysis of the Spinal Cord in Bone Cancer Pain Rats by Two-Dimensional Gel Electrophoresis
}

\author{
Minjing Peng \\ Hubei University of Medicine \\ Yanqiong Wu \\ Hubei University of Medicine
}

Shanchun Su

Hubei University of Medicine

Shengjun Wan

Hubei University of Medicine

\section{Lingyu Zhou}

Hubei University of Medicine

Yifu Jia

Hubei University of Medicine

Xiaohui Li

Hubei University of Medicine

Xueqin Xu

Hubei University of Medicine

Yan Gao

Hubei University of Medicine

Changbin Ke ( $\square$ changbinke-iap@taihehospital.com )

Hubei University of Medicine

\section{Research Article}

Keywords: proteomics, spinal cord, bone cancer pain, two-dimensional gel electrophoresis

Posted Date: December 28th, 2021

DOI: https://doi.org/10.21203/rs.3.rs-1159636/v1

License: (c) (i) This work is licensed under a Creative Commons Attribution 4.0 International License. Read Full License 


\section{Abstract}

Background: Bone cancer pain (BCP) is a common chronic pain that is caused by a primary or metastatic bone tumor. It is refractory to currently available clinical treatment owing to its complicated underlying mechanisms.

Methods: In this study, we used proteomics approaches to investigate expressional changes of the rat spinal cord proteome from 7 to $21 \mathrm{~d}$ after inoculation. Proteins from the rat L4-6 spinal cord homogenates of BCP and Sham animals were fractionated by two-dimensional (2-DE) gel electrophoresis to produce a high-resolution map of the spinal cord soluble proteins. Proteins showing altered expression levels between BCP and Sham were selected.

Results: A total of 60 spots were obtained, and isolated proteins were in-gel trypsin-digested and the resulting peptides were analyzed by matrix-assisted laser desorption/ionization-time of flight (MALDI-TOF) mass spectrometry. Using the mass spectrometric data, 34 differentially expressed proteins (DEPs) were identified. GO analysis of the identified proteins allowed us to explore the function of the represented proteins. Conclusions: Based on these results, the identified proteins may contribute to the maintenance of $B C P$, and may provided new or valuable information in the discovery of new therapeutic targets for BCP.

\section{Background}

Bone cancer pain (BCP) is a common symptom in patients with primary bone tumor and secondary bone metastasis. Recent data indicated that approximately $40 \%-80 \%$ of patient with advanced-stage disease or metastatic cancer will experience significant cancer pain [1]. Many common tumors, including breast cancer, prostate cancer, lung cancer, have a high tendency to metastasize to the bone, causing obvious BCP. With the growth of tumor and the destruction of bone, the characteristics of BCP shows allodynia, hyperalgesia, spontaneous ongoing pain and incident breakthrough pain [2]. Currently, the main therapeutic methods are analgesic (NSAIDs and opioid drugs), surgery, radiotherapy, radiofrequency ablation, nerve block, bisphosphonates, which can alleviate the pain of cancer patients to a certain extent [3]. However, due to the severe side - effects of drugs and limited treatment, there are still many patients with cancer whose pain is not effectively controlled and seriously affect the quality of the patients' life.

At present, the research on the mechanism of BCP mainly focuses on the changes of tumor microenvironment and peripheral and central sensitization. Tumor cells and their stromal cells, cytokines produced by inflammatory cells, sustained activation of osteoclasts, tumor growth, as well as compression and injury of nerves may all be associated with bone cancer pain [4]. Spinal cord is the primary central of pain information transmission and integration, and its sensitization is the main mechanism of chronic pain [5]. Altered expression of proteins in the spinal cord are likely a consequence of the tumor itself or metastasized to bone caused pain. How these proteins are implicated in the pathogenesis of BCP remains unclear. Therefore, it may be a promising method to analyze the changes of spinal cord protein in order to seek for potential specific protein to elucidate the molecular mechanisms of $\mathrm{BCP}$ and to improve the life quality of patients with cancer.

Proteomics is the study of cell or tissue expressed in specific physiological or pathological condition of all kinds of protein. Utilizing the two-dimensional gel electrophoresis and mass spectrometry technology, as well as as the combination of bioinformatics for protein type, structure, positioning, and the research and analysis on the interaction between protein and protein, in order to further study and understand the pathogenesis of BCP provides reference [6]. 
In this study, we first implanted carcinoma cells into the tibial plateau of rats to establish a model of BCP. We used two-dimensional (2D) gel electrophoresis combined with matrix-assisted laser desorption ionization time-of-flight mass spectrometry (MALDI-TOF-MS) to perform a global analysis of the expressional changes in the rat spinal cord protein from 7 to $21 \mathrm{~d}$ after tumor injection. This study will provide valuable information in the way of understanding the pathogensis and discovering new therapeutic targets for BCP.

\section{Materials And Methods}

\section{Cells and animals}

The Walker 256 rat mammary gland carcinoma cells used in the experiment were provided by the Institute of Anesthesiology \& Pain (IAP), Taihe Hospital. Healthy female Sprague-Dawley (SD) rats weighing 180-220 g were kindly provided by Institute of Laboratory Animal Science, Hubei University of Medicine (Hubei, China). All rats ( $n=$ 12-14 for each group) were kept in a control room under a constant temperature $\left(22 \pm 2^{\circ} \mathrm{C}\right)$ and humidity $(50 \pm 20 \%)$ with a rugular $12 \mathrm{~h}$ light/dark cycle. Rats had free access to standard diet and water. The experimental procedures and protocols in this study were approved by the Animal Care and Use Committee of Hubei University of Medicine ( Hubei, China) and were in accordance with the guidelines of the International Association for the Study of Pain (IASP).

\section{Establishment of BCP model}

Walker 256 cells $\left(20 \mu \mathrm{L}, 5 \times 10^{7}\right.$ cells $\left./ \mathrm{mL}\right)$ were injected into the tibial plateau of SD rats weighing $180-220 \mathrm{~g}$ to establish the BCP model. The rats were anesthetized with (3\% for induction, $5 \%$ for maintenance) and placed on an operating table in the supine position. The right hind leg was slowly shaved and disinfected with $0.5 \%$ iodine. A long skin incision of about $0.5 \mathrm{~cm}$ was made at the right tibial plateau of rats. A 23-gauge needle was insert into the tibial plateau for making a drilled hole. A $20 \mu \mathrm{L}$ volume of Walker 256 rat mammary cancer cells $\left(5 \times 10^{7}\right.$ cells $/ \mathrm{mL}$ ) or PBS was slowly injected into the intramedullary space of a rat's tibias plateau with a $25-\mu \mathrm{L}$ glass microinjector. The syringe was left in the place for an additional 2 min to prevent the carcinoma cells from leaking out along the injection track, and then sealed with bone wax while the syringe was removed. The wound was carefullly sterilized and stitched up. After the operation, the rat was placed on a constant temperature resuscition blanket and put back into the cage after waking up.

\section{Behavioral test of pain}

The paw withdraw threshold (PWT) of rats were measured preoperatively and on postoperative days (PODs) 7,14 , and 21 with a dynamic plantar esthesiometer (Ugo Basile, Comerio, Italy), an automated version of the von Frey hair test. The measurements on each day were conducted from 8:00 to 11:00 a.m. in a quiet room. The rats were placed in a transparent plexiglass cage $(20 \mathrm{~cm} \times 25 \mathrm{~cm} \times 15 \mathrm{~cm})$ on an elevated mental mesh floor and were kept quiet for $30 \mathrm{~min}$ before testing. From bottom to top, Von Frey filaments ( $0.5 \mathrm{~mm}$ diameter) stimulate the middle skin of the bottom of the right. The stimulus intensity was gradually increased from $0 \mathrm{~g}$ to $50 \mathrm{~g}$ within $20 \mathrm{~s}$ When the rats showed a contraction response, the intensity of the stimulus was stopped automatically. Recording the pressure value. Each rat was measured three times at an interval of $10 \mathrm{~min}$, and the average of three values was used for data analysis.

\section{Protein sample preparation}


From time points were set: 7, 14, and 21 day after inoculation, the rats ( $n=3$ - 4 for each group) were intraperitoneally injected with $10 \%$ chloral hydrate $(0.1-0.3 \mathrm{~mL} / 100 \mathrm{~g})$ for deep anesthesia at each time point. The lumbar spine was rapidly cut and the surrounding tissues were separated to obtain the L4-6 spinal cord. The obtained spinal cord tissue was placed into a $1.5 \mathrm{~mL}$ cryopreservation tube and then stored in a refrigerator at $-80^{\circ} \mathrm{C}$. The extracted spinal cord tissues were lysed in a lysis buffer (7 M urea, $2 \mathrm{M}$ thiourea, $100 \mathrm{mM} \mathrm{DTT}, 4 \%$ CHAPS, 0.5 mM EDTA, 40 mM Tris, 2\% NP40, 1\% TritonX-100, 5 mM PMSF, and 2\% pharmalyte). The lysates were homogenated rapidly for $3 \mathrm{~min}$, placed at room temperature for $1 \mathrm{~h}$, mixed intermittently during the period, and Centrifuged at $15000 \mathrm{rpm}$ for $1 \mathrm{~h}$ at $4^{\circ} \mathrm{C}$. The supernatant was taken as the total protein of the tissue and was subsequently stored at $-80^{\circ} \mathrm{C}$. The concentration of the total protein was determined by 2-D Quant-Kit (GE Healthcare, Pittsburgh, PA, U.S.A.) according to the manufacturer's instructions.

\section{Two-dimensional gel electrophoresis (2-DE) and image analysis}

The spinal cord protein samples ( $600 \mu \mathrm{g}$ of protein) were diluted well to $250 \mu \mathrm{L}$ the hydration solution, which included $8 \mathrm{M}$ urea, 2\% CHAPS, $15 \mathrm{mM}$ DTT, 0.5\% IPG buffer at pH 3-10. The mixtures were loaded onto $17 \mathrm{~cm} \mathrm{pH} \mathrm{3-}$ 10 IPG strips (Bio-Rad, Hercules, CA, USA) by Using a Protean IEF cell (Bio-Rad, Hercules, CA, USA). IEF was carried out at $20^{\circ} \mathrm{C}$ under the following schedule: $500 \mathrm{~V}$ for $1 \mathrm{~h}, 1,000 \mathrm{~V}$ for $1 \mathrm{~h}, 8,000 \mathrm{~V}$ for $2 \mathrm{~h}, 8,000 \mathrm{~V}$ for $3 \mathrm{~h}$, and finally, $500 \mathrm{~V}$ overnight. After IEF, the focused IPG strips were equilibrated in equilibration solution containing $1 \%$ DTT, 50 $\mathrm{mM}$ Tris- $\mathrm{HCl}(\mathrm{pH} 8.8), 6 \mathrm{M}$ urea, 30\% (v/v) glycerol, and 2\% (w/v) sodium dodecyl sulfate (SDS) for $15 \mathrm{~min}$ and then by further incubation in the same solution, except for replacement of DTT with $2.5 \%$ iodoacetamide for an additional 15 min period. Gel stripes were placed onto a top of $12.5 \%$ polyacrylamide gels for resolution in the seconed dimension. Proteins were separated by running the gels at $5 \mathrm{~W} / \mathrm{gel}$ for $30 \mathrm{~min}$, and then at $17 \mathrm{~W} / \mathrm{gels}$ at $10^{\circ} \mathrm{C}$ until the bromophenol blue dye reached the bottom of the gels. After two-demensional gel electrophoresis (2$D E)$, The gels were stained with silver methods to make it compatible with mass spectrometry, scanned using GS800 Calibrated Densitometer (Bio-Rad), and analyzed by using Quantity One and Bio-Rad PDQuest software 8.0.1. PDQuest software successively performed point detection, background subtraction, standardization, matching and comparative difference analysis for the differentially expressed protein spots in 2-DE images of spinal cord tissues. Finally, It was believed that Proteins presenting as spots with $\geq 1.5$ fold and $p<0.05$ changes (Student's t-test) in expression were considered as statistically significant altered proteins.

\section{MALDI-TOF-MS analysis and protein identification}

The statistically significant protein spots were selected, excised manually from each 2-DE and the protein was digested as previously study described [7]. The excised protein spots were proteolyzed in-gel with trypsin and resulting tryptic peptides were subsequently extracted and dried under vacuum. The in-gel digested peptides were analyzed with MALDI-TOF-MS. Combined peptide mass fingerprinting (PMF) and tandem mass spectrometry (MS/MS) queries were searched against the NCBI database, using the MASCOT search engine from Matrix Science (http://www.matrixscience.com/) to identify the proteins. Proteins matching more than five peptides and with a Mascot score higher than 60 were considered significant $(p<0.05)$ [8]. To identify the correct protein from a Mascot results list, MOWSE score and species had to be considered.

\section{Bioinformatics analysis}

To functionally annotate the correlated genes, gene ontology (GO) and pathway analysis, GI numbers of differentially identified proteins by 2D electrophoresis were uploaded to the Database for Annotation, Visualization and Integrated Discovery (DAVID) functional annotation tool (http://david.ncifcrf.gov/tools.jsp). The enrichment 
analysis was done using Fisher exact test. Functional categories with $p<0.05$ were considered to significant after

multiple term testing by Bonferroni correction. The protein-protein interactions (PPIs) network was predicted using Search Tool for the Retrieval of Interacting Genes (STRING; http://string-db.org) (version 10.0) online database. In the present study, PPIs network of DEPs were constructed using STRING database, and an interaction with a combined score 0.4 was considered statistically significant. Cytoscape (version 3.4.0) is an open source bioinformatics software platform for visualizing molecular interaction networks [9].

\section{Statistical analysis}

The GraphPad Prism 7 statistic software was used for data analysis calculations. The data are presented as mean \pm standard error of the mean. One-way analysis of variance (ANOVA) was used to compare differences between groups. $p<0.05$ were considered statistically significant.

\section{Results}

\section{The PWT was decreased in rats with BCP}

The PWT of the rats were measured on the day $0,7,14$, and 21 after inoculation. As Fig. 1 shows, there was no significant difference in the basic PWT for all rats before inoculation. The PWT was significantly lower in BCP rats compared to sham rats $(p<0.05)$ on days 7 to 21 , While the pain threshold of the Sham group rats was relatively stable (Fig. 1).

\section{Establishment of 2-DE pattern}

2-DE with clear background and high resolution were established for the Sham and BCP group on the day 7, 14, and 21 after inoculation. Representative silver-stained gels are shown in Fig. 2A. PDQuest software was used to analyze the two groups of maps, and about 1000 protein points were detected on each map. These protein points were mainly distributed in the region of $\mathrm{pH} 3-10,10-100 \mathrm{kDa}$ molecular weight. For the results, a total of 60 protein spots exhibited significant differential expression in the BCP group, and values were distributed from 4.0 to 9.0 isoelectric point and 10 to $100 \mathrm{kDa}$ (molecular mass). Compared to the Sham group, 14, 6, and 12 protein spots were downregulated on the day of 7, 14, and 21 after inoculation, respectively. Meanwhile, 10, 4, and 14 protein spots were upregulated. Fig 2B shows four representative differentially expressed protein spots were magnified in the lumbar spinal cord of the two groups of rats at each time point. The 60 protein spots with significant differential expression were selected for MALDI-TOF-MS.

\section{Proteins identified by MALDI-TOF-MS}

Represented protein spots were excised from the 2-DE and analyzed for protein identification by MALDI-TOF-MS. The PMF was obtained and analyzed using the MASCOT search engine against the NCBI database. The resulting protein was determined by comprehensively considering the corresponding experimental PI, Mr, the number of matched - peptides, and sequence coverage. Among 60 protein spots, 34 DEPs were successfully identified by PMF. The data of all identified protein spots were described in Table 1.

\section{GO enrichment pathway and PPI network analysis of DEPs}

To analyze the biological classification of the 34 DEPs, functional annotation clustering analyses were based on GO annotation category. Go enrichment analysis was conducted using DAVID online software according to three 
main annotation categories, namely biological process category, cellular component category and molecular function category. Among 34 proteins, 21 DEPs were clustered. As shown in Fig. 3, GO biological process category revealed that these DEPs were mainly clustered in actin filament organization, hippocampus development, oxidation-reduction process; GO cellular component category demonstrated that a majority of above proteins were linked to the extracellular exosome, myelin sheath, cytoplasm, neuron projection, growth cone; GO molecular function category displayed that those proteins were mainly enriched in cytoskeleton, actin binding, toxic substance binding.

To better illuminate the potential molecular mechanism of BCP, PPI network was analyzed using STRING database and visualized using Cytoscape online tool to evaluate the relationship among the DEPs. As diaplayed in Fig. 4, PPI revealed that remarkable interactions existed.

\section{Discussion}

BCP is a kind of chronic pain with unique and complicated mechanism, which is the most common symptom of pain for the patient with cancer. For a long time, it has seriously affect the life quality of patients with cancer and brought oppressive pain to patients and their families. Spinal cord is the primary central of pain information transmission and integration, and its sensitization is the main mechanism of chronic pain. Rat spinal cord contains thousands of proteins, which may be closely related to the development of BCP. Therefore, it may be a promising way to analyze the profile of spinal cord protein alterations in order to try finding potential biomarker to elucidate the pathogenesis of BCP [10]. Nowadays, proteomic analysis is widely considered as a valuable strategy to conduct mechanistic studies [11]. In order to find potential molecules and elucidate the regulatory mechanisms of BCP, Proteomic approaches were applied.

In this study, we first implanted carcinoma cells into the tibial plateau of rats to establish a model of BCP. The PWT of rats ipsilateral paw was measured on the day 0, 7, 14 and 21 after inoculation. With the tumor growth, the PWT decreased obviously in BCP rats, it suggested that the bone cancer pain animal model was successfully established.

Proteomic method of 2-DE gels electrophoresis was used to analyze the rat lumbar spinal cord. For the results, a total of 60 DEPs were identified, including 32 downregulated proteins and 28 upregulated proteins. The 60 protein spots with significant differential expression were selected for MALDI-TOF-MS analysis. Among 60 protein spots, 34 DEPs were successfully identified by PMF.

We analyzed the differentially expressed proteins, and taking into consideration their function annotation, identified several proteins that may be related to the molecular mechanism of the BCP. For example, cofilin1, tropomodulin-2 (Tmod2) and tropomyosin beta chain (Tpms), which are associated with actin filament organization function. Cofilin1 is an actin-binding protein, the primary function of which is dynamic reorganization of actin cytoskeleton. It plays an important role in regulating actin dynamic, affecting synaptic transmission and plasticity. A previous study reported that the expression of cofilin1 is down-regulated in DRG and spinal cord of BCP, suggesting that cofilin1 is involved in the formation and development of BCP [12]. Our results also showed cofilin downregulation on the day 7 after inoculation in the BCP model. Actin filaments have a wide range of functions in membrane morphology, cell movement, vesicle transport, neurite development, and synaptic communication, and are considered to play an important role in synaptic plasticity [13]. The state of actin (as monomers or polymeric strands) and the length of the filaments are controlled by numerous actin-regulatory proteins. Tmod 2 is a 
protein that binds to the slow-growing (pointed) ends of actin filaments (F-actin), preventing both elongation and depolymerization. Tpm bind along the length of actin filaments and prevents filament depolymerization. In fact, the pointed-end capping activity of Tmod2 is greatly enhanced by association with Tpm, which suggests that the two proteins function as a complex to stabilize the filament and regulate its length. In our results, Tmod2 was downregulated and Tpm was upregulated in the BCP model, suggesting that actin filaments were activated and lose staility, which increased the growth rate of actin filaments, and finally contributed to enhanced of information synaptic transmission of dendritc spines in neurons, inducing the occurrence of BCP. It has been reported knockout of Tmod2 increased long -term potentiation (LTP) in brain slices [14]. This fully suggests that Tmod2 is associated with synaptic information transmission and may be involved in the occurrence and development of BCP.

Glia maturation factor- $\beta$ (GMFB) is considered to be a growth and differentiation factor for both glia and neurons, Which is expressed predominantly in the central nervous system (CNS) [15]. The major cells that express GMFB in the nervous system are glial cells, including astrocytes, Bergmann glia in the cerebellum, Schwann cells in the peripheral nervous system (PNS). It is commonly accepted that reactive oxygen species (ROS) are important byproducts of metabolism and participate in many pathophysiological processes. Recent studies have shown that ROS are involved in sensory transmission and regulation and are an important factor leading to carcinogenic pain. As part of the cellular antioxidant system, Copper-zinc superoxide dismutase (Cu-Zn SOD) can scavence ROS, reduce oxidative stress at the spinal cord level and relieve bone cancer pain through its own antioxidant action and protective antioxidant action of prdx4 [16]. A previous study reported that overexpression of GMFB using an adenovirus vector carrying GMFB cDNA in C6 rat glioma cells led to the activation of NF-KB as well as an increase in Cu-Zn SOD expression [17]. In our study, GMFB is downregulated on the day 7 after surgery in the BCP model. It suggest that the production of reactive oxygen species increases in the BCP, while the stimulation of Cu-Zn SOD is weakened by the down-regulation of GMFB, and the expression of Cu-Zn SOD is reduced, which forms oxidative stress and stimulates the production of various harmful substances by the cells, causing the abnormal release of neurotransmitters as well as the abnormal activation of corresponding receptors, resulting in bone cancer pain. Therefore, GMFB is a valuable molecule for further functional research in BCP.

Calpain is a family of calcium-dependent intracellular cysteine protease, the activity of which is dependent on intracellular calcium levels. They participate in a variety of cellular processes such as signal transduction, cell proliferation, cell cycle progression, differentiation, apoptosis, membrance fusion, necrosis and platelet activation, etc [18]. Among them, Calpain is known to exert restrictive proteolysis on its specific substrates, particularly IKBa, C-Jun, and c-Fos, all of which are essential molecular players in osteoclastogenesis [19]. Studies have suggested that inhibition of the activity of the protease calpain reduce the development of acute and chronic inflammation [20]. On the other hand, a previous study also reported that calpain inhibitor reduces BCP possibly through inhibition of osteoclastogenesis in rat BCP model [21]. However, Calpain was downregulated in our study. Therefore, the downregulation of Calpain may suggest activation of a otective mechanism in BCP model, and could reduce the extent of pain.

The N-myc downstream-regulated gene (NDRG) family consists of four members (NDRG1 4) that are differentially expressed in various organs and important cellular processes, such as cell proliferation, apoptosis, differentiation, development, and stress reponse [22]. As a member of the NDRG family, NDRG family member 2 (NDRG2) is predominantly expressed in astrocytes of the central nervous system (CNS). Its function in the CNS is mainly related to its role in astrocyte activity. The expression of NDRG2 is ubiquitous in astrocytes, and mostly colocalizes with the astrocyte marker glial fibrillary acidic protein (GFAP). NDRG2, which is involved in not only the regulation of apoptosis, blood-brain barrier integrity, glutamate clearance and other cellular metabolic processes, 
but also stress responses, is commonly regarded as a tumor suppressor [23,24]. NDRG2 has been found to be expressed in neurons, playing an important in neural differentiation, synapse formation, and axon survival [25]. A recent study revealed the correlations between Glutamatergic and GABAergic nerve terminals and NDRG2 immunopositive astrocytic processes [26]. The expression of the glutamate transporters glutamate aspartate transporter (GLAST) and glutamate transporter 1 (GLT-1) were increased by deletion of NDRG2 in glialtransmission. A previous study demonstrated that NDRG2 is implicated in many neurological diseases including glioma, stroke, neurodegeneration and psychiatric disorders. However, the expression changes of NDRG2 in BCP have been rarely reported. Our study found that the expression of NDRG2 in BCP model was up-regulated, Considering the role of NDRG2 in astrocytes, NDRG2 may induce the activation of spinal astrocytes to participate in the occurrence and maintenance of bone cancer pain.

GO enrichment analysis revealed that the biological functions of the differentially expressed proteins relate mainly to actin filament organization, hippocampus development, oxidation-reduction process and give an insight into the underlying molecular mechanisms of the BCP. The functions of these proteins in biological processes should be further validated.

\section{Conclusion}

The comparative proteomics study is an effective platform to identify DEPs that may be implicated in the pathogenesis of BCP. Among 60 protein spots 34 DEPs were successfully identified by PMF. DEPs identified in the present study help us understand the molecular mechanisms underlying the carcinogenesis and progression of $\mathrm{BCP}$, and provided candidate targets for diagnosis and treatment of BCP.

\section{Declarations}

\section{Ethics approval and consent to participate}

This study was approved by the ethics Committee of Hubei University of Medicine.

\section{Consent for publication}

Not applicable.

\section{Availability of supporting data}

The datasets used and/or analysed during the current study are available from the corresponding author on reasonable request.

\section{Competing interests}

The submission is not under review at any other publication, in whole or in part, and all the authors listed have approved the enclosed manuscript. All the authors declare no financial conflicts of interest and have fulfilled the criteria of authorship for the manuscript.

\section{Funding}

This study was supported by the National Natural Science Foundation of China (N0.81971060), Natural Science Foundation of Hubei Province (NO.2020CFB342), Health Commission of Hubei Province scientific research project 
(WJ2021F036), Department of Education of Hubei Province (B2020109), Scientific and Technological Project of Shiyan City (21Y30, 21Y41), and the Innovative Research Program for Graduates of Hubei University of Medicine (NO.YC2019005).

\section{Authors' contributions}

Changbin Ke designed the experiments, Minjing Peng and Yanqiong Wu wrote and improved the manuscript, Shanchun Su, Yifu Jia and Shengjun Wan executed the experiments, Xiaohui Li, Xueqin Xu, Lingyu Zhou and Yan Gao implemented the experiments of Two-dimensional gel electrophoresis and Bioinformatics analysis. All authors read and approved the final manuscript.

\section{Acknowledgements}

Not applicable.

\section{Authors' information}

${ }^{1}$ Institute of Anesthesiology \& Pain (IAP), Department of Anesthesiology, Taihe Hospital, Hubei University of Medicine, Shiyan, Hubei, China

${ }^{2}$ Department of PET Center, Taihe Hospital, Hubei University of Medicine, Shiyan, Hubei, China.

\section{References}

1. J. HAVELIN, I. IMBERT, and D. SUKHTANKAR, et al.,"Mediation of Movement-Induced breakthrough cancer pain by IB4-Binding nociceptors in rats," J. Neurosci., 37, 5111-22 (2017).

2. Y. XU, J. LIU, and M. HE, et al.,"Mechanisms of PDGF siRNA-mediated inhibition of bone cancer pain in the spinal cord,"Sci. Rep., 6, 27512 (2016).

3. T. MEUSER, C. PIETRUCK, and L. RADBRUCH, et al.,"Symptoms during cancer pain treatment following WHOguidelines: A longitudinal follow-up study of symptom prevalence, severity and etiology,"Pain, 93, 247-57 (2001).

4. P. MANTYH,“Bone cancer pain: Causes, consequences, and therapeutic opportunities,”Pain, 154, S54-62 (2013).

5. S. FALK, and A. H. DICKENSON,“Pain and nociception: Mechanisms of cancer-induced bone pain,” J. Clin. Oncol., 32, 1647-54 (2014).

6. W. C. CHO,"Mass spectrometry-based proteomics in cancer research,”Expert Rev. Proteomics, 14, 725-27 (2017).

7. M. Q. HUANG, X. X. CHENG, and S. L. CHEN, et al.,'Analysis of differentially expressed proteins in Muscovy duck embryo fibroblasts infected with virulent and attenuated Muscovy duck reovirus by two-dimensional polyacrylamide gel electrophoresis,"J. Vet. Med. Sci., 79, 2063-69 (2017).

8. G. CAI, B. CHEN, and Z. LI, et al.,"The different expressed serum proteins in rhCygb treated rat model of liver fibrosis by the optimized two-dimensional gel electrophoresis,"PLoS One, 12, e177968 (2017).

9. L. LI, Q. LEI, and S. ZHANG, et al.,"Screening and identification of key biomarkers in hepatocellular carcinoma: Evidence from bioinformatic analysis,"Oncol. Rep., 38, 2607-18 (2017). 
10. H. LIU, J. LANG, X. WANG, and S. WU,“Comparative proteomic analysis of human adenomyosis using twodimensional gel electrophoresis and mass spectrometry,"Fertil. Steril., 89, 1625-31 (2008).

11. R. C. STEIN, and M. J. ZVELEBIL,"The application of 2D Gel-Based proteomics methods to the study of breast cancer,"J. Mammary Gland Biol., 7, 385-93 (2002).

12. X. XIE, X. LI, and H. ZHAO, et al.,"Expression of synaptic proteins in the DRGs and spinal cord in rats with bone cancer pain,"Neurophysiology, 51, 9-17 (2019).

13. K. T. GRAY, A. S. KOSTYUKOVA, and T. FATH,“'Actin regulation by tropomodulin and tropomyosin in neuronal morphogenesis and function,"Mol. Cell. Neurosci., 84, 48-57 (2017).

14. P. R. COX, V. FOWLER, and B. XU, et al.,"Mice lacking tropomodulin-2 show enhanced long-term potentiation, hyperactivity, and deficits in learning and memory,"Mol. Cell. Neurosci., 23, 1-12 (2003).

15. J. FAN, T. FONG, and X. CHEN, et al.,"Glia maturation factor-beta: A potential therapeutic target in neurodegeneration and neuroinflammation,"Neuropsychiatr. Dis. Treat., 14, 495-504 (2018).

16. W. YAO, H. ZHAO, and R. SHI, et al.,"Recombinant protein transduction domain-Cu/Zn superoxide dismutase alleviates bone cancer pain via peroxiredoxin 4 modulation and antioxidation,"Biochem. Bioph. Res. Co., 486, 1143-48 (2017).

17. R. LIM, A. ZAHEER, and J. A. KRAAKEVIK, et al.,'Overexpression of glia maturation factor in c6 cells promotes differentiation and activates superoxide dismutase,"Neurochem. Res., 23, 1445-51 (1998).

18. K. SUZUKI, S. HATA, Y. KAWABATA, and H. SORIMACHI,“Structure, activation, and biology of calpain,”Diabetes, 53 Suppl 1, S12-18 (2004).

19. M. PARIAT, C. SALVAT, and M. BEBIEN, et al.,"The sensitivity of c-Jun and c-Fos proteins to calpains depends on conformational determinants of the monomers and not on formation of dimers,"Biochem. J., 345 Pt 1, 129 38 (2000).

20. S. CUZZOCREA, M. C. MCDONALD, and E. MAZZON, et al.,"Calpain inhibitor I reduces the development of acute and chronic inflammation,"Am. J. Pathol., 157, 2065-79 (2000).

21. J. Y. XU, Y. JIANG, W. LIU, and Y. G. HUANG,“Calpain inhibitor reduces cancer-induced bone pain possibly through inhibition of osteoclastogenesis in rat cancer-induced bone pain model,"Chin. Med. J .(Engl), 128, 1102-07 (2015).

22. S. L. SCHONKEREN, M. MASSEN, and R. van der HORST, et al.,'Nervous NDRGs: The N-myc downstreamregulated gene family in the central and peripheral nervous system,"Neurogenetics, 20, 173-86 (2019).

23. F. KANG, Y. WANG, Y. LUO, and Y. ZHANG,"NDRG2 gene expression pattern in ovarian cancer and its specific roles in inhibiting cancer cell proliferation and suppressing cancer cell apoptosis,"J. Ovarian Res., 1348 , (2020).

24. J. MA, W. LIU, and H. GUO, et al.,"N-myc downstream-regulated gene 2 expression is associated with glucose transport and correlated with prognosis in breast carcinoma,"Breast Cancer Res., 16, R27 (2014).

25. C. MITCHELMORE, S. BÜCHMANN-MØLLER, and L. RASK, et al.,"NDRG2: A novel Alzheimer's disease associated protein,"Neurobiol. Dis., 16, 48-58 (2004).

26. G. FLÜGGE, C. ARAYA-CALLIS, and E. GAREA-RODRIGUEZ, et al.,"NDRG2 as a marker protein for brain astrocytes,"Cell Tissue Res., 357, 31-41 (2014).

\section{Tables}


Table 1 Identification of 34 proteins differentially expressed in the Sham and BCP groups 


\begin{tabular}{|c|c|c|c|c|c|c|c|}
\hline $\begin{array}{l}\text { Spot } \\
\text { No. }\end{array}$ & $\begin{array}{l}\text { NCBI } \\
\text { accession } \\
\text { No. }\end{array}$ & Protein name & $\begin{array}{l}\text { Molecular } \\
\text { weight(Da) }\end{array}$ & $\mathrm{pl}$ & $\begin{array}{l}\text { Protein } \\
\text { score }\end{array}$ & $\begin{array}{l}\text { Sequence } \\
\text { co- } \\
\text { verage(\%) }\end{array}$ & $\begin{array}{l}\text { expression } \\
\text { variation } \\
\text { in spinal } \\
\text { cord }\end{array}$ \\
\hline A02 & gi 149017236 & rCG49429 & 25375 & 5.33 & 177 & 36 & down \\
\hline A03 & $\begin{array}{l}\mathrm{gi} \\
13928838\end{array}$ & tropomodulin-2 & 39468 & 5.34 & 175 & 32 & down \\
\hline A04 & $\begin{array}{l}\text { gi } \\
149037563\end{array}$ & rCG55630, isoform CRA_a & 38366 & 6.8 & 284 & 52 & down \\
\hline A06 & $\begin{array}{l}\text { gi } \\
1794205\end{array}$ & $\begin{array}{l}\text { calpain small subunit, } \\
\text { partial }\end{array}$ & 28176 & 5.29 & 192 & 33 & down \\
\hline A08 & gi 293347718 & $\begin{array}{l}\text { PREDICTED: similar to } \\
\text { HT014 }\end{array}$ & 24405 & 5.47 & 306 & 66 & down \\
\hline A09 & $\begin{array}{l}\text { gi } \\
6978859\end{array}$ & ferritin heavy chain & 21257 & 5.62 & 197 & 46 & down \\
\hline A10 & $\begin{array}{l}\text { gi } \\
8393101\end{array}$ & cofilin-1 & 18749 & 8.22 & 237 & 53 & down \\
\hline A13 & $\begin{array}{l}\mathrm{gi} \\
62665569\end{array}$ & PREDICTED: destrin & 18793 & 7.57 & 132 & 18 & down \\
\hline A14 & $\begin{array}{l}\text { gi } \\
149033532\end{array}$ & $\begin{array}{l}\text { glia maturation factor, } \\
\text { beta, } \\
\text { isoform CRA_a }\end{array}$ & 13012 & 5.07 & 106 & 44 & down \\
\hline B03 & $\begin{array}{l}\mathrm{gi} \\
13928850\end{array}$ & $\begin{array}{l}\text { D-3-phosphoglycerate } \\
\text { dehydrogenase }\end{array}$ & 57256 & 6.28 & 314 & 25 & up \\
\hline B05 & $\begin{array}{l}\text { gi } \\
8393823\end{array}$ & $\begin{array}{l}\text { neurofilament medium } \\
\text { polypeptide }\end{array}$ & 95706 & 4.76 & 399 & 31 & up \\
\hline B06 & $\begin{array}{l}\mathrm{gi} \\
149037563\end{array}$ & rCG55630, isoform CRA_a & 38366 & 6.8 & 170 & 30 & up \\
\hline B07 & gi 224839 & tubulin T beta15 & 50361 & 4.79 & 338 & 33 & up \\
\hline B10 & $\begin{array}{l}\text { gi } \\
157819655\end{array}$ & heme-binding protein 2 & 22993 & 4.51 & 224 & 33 & up \\
\hline C01 & gi 55628 & unnamed protein product & 70670 & 6.09 & 389 & 31 & down \\
\hline $\mathrm{CO2}$ & gil 55628 & unnamed protein product & 70670 & 6.09 & 341 & 33 & down \\
\hline $\mathrm{C06}$ & $\begin{array}{l}\text { gi } \\
6978859\end{array}$ & ferritin heavy chain & 21257 & 5.62 & 142 & 20 & down \\
\hline D01 & gi 55628 & unnamed protein product & 70670 & 6.09 & 455 & 35 & up \\
\hline D02 & $\begin{array}{l}\text { gi } \\
19424278\end{array}$ & protein NDRG2 & 39587 & 5.3 & 136 & 32 & up \\
\hline D03 & $\begin{array}{l}\text { gil } \\
66730475\end{array}$ & tropomyosin beta chain & 32995 & 4.63 & 314 & 42 & up \\
\hline
\end{tabular}




\begin{tabular}{|c|c|c|c|c|c|c|c|}
\hline E02 & gil & dynactin subunit 2 & 44235 & 5.14 & 421 & 44 & down \\
\hline E03 & gil 81867103 & NDRG1-related protein & 41095 & 5.16 & 66 & 24 & down \\
\hline E06 & gil 19424278 & protein NDRG2 & 39587 & 5.3 & 96 & 25 & down \\
\hline E07 & $\begin{array}{l}\text { gil } \\
19424278\end{array}$ & protein NDRG2 & 39587 & 5.3 & 88 & 19 & down \\
\hline E10 & $\begin{array}{l}\text { gil } \\
149032469\end{array}$ & $\begin{array}{l}\text { guanine nucleotide binding } \\
\text { protein, alpha o, isoform } \\
\text { CRA_b }\end{array}$ & 35118 & 5.18 & 181 & 28 & down \\
\hline F01 & $\begin{array}{l}\text { gil } \\
1000439\end{array}$ & grp75 & 73984 & 5.87 & 332 & 20 & up \\
\hline F03 & gi| & $\begin{array}{l}\text { T-complex protein } 1 \\
\text { subunit beta }\end{array}$ & 57764 & 6.01 & 187 & 28 & up \\
\hline F04 & gi| 57671 & ribonuclease inhibitor & 51584 & 4.64 & 249 & 42 & up \\
\hline F08 & 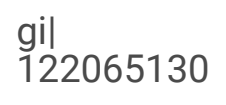 & Annexin A3 & 36569 & 5.96 & 297 & 52 & up \\
\hline F10 & $\begin{array}{l}\text { gil } \\
11693154\end{array}$ & $\begin{array}{l}\text { platelet-activating factor } \\
\text { acetylhydrolase IB subunit } \\
\text { beta }\end{array}$ & 25736 & 5.57 & 117 & 27 & up \\
\hline F11 & $\begin{array}{l}\text { gil } \\
16758298\end{array}$ & $\begin{array}{l}\text { proteasome subunit beta } \\
\text { type-7 precursor }\end{array}$ & 30250 & 8.13 & 206 & 14 & up \\
\hline F12 & $\begin{array}{l}\text { gil } \\
16758274\end{array}$ & peroxiredoxin-4 precursor & 31216 & 6.18 & 130 & 22 & up \\
\hline F13 & gil 94400790 & heat shock protein beta- 1 & 22865 & 6.12 & 213 & 38 & up \\
\hline F14 & gil 8393910 & $\begin{array}{l}\text { phosphatidylethanolamine- } \\
\text { binding protein } 1\end{array}$ & 20902 & 5.48 & 117 & 57 & up \\
\hline
\end{tabular}

\section{Figures}




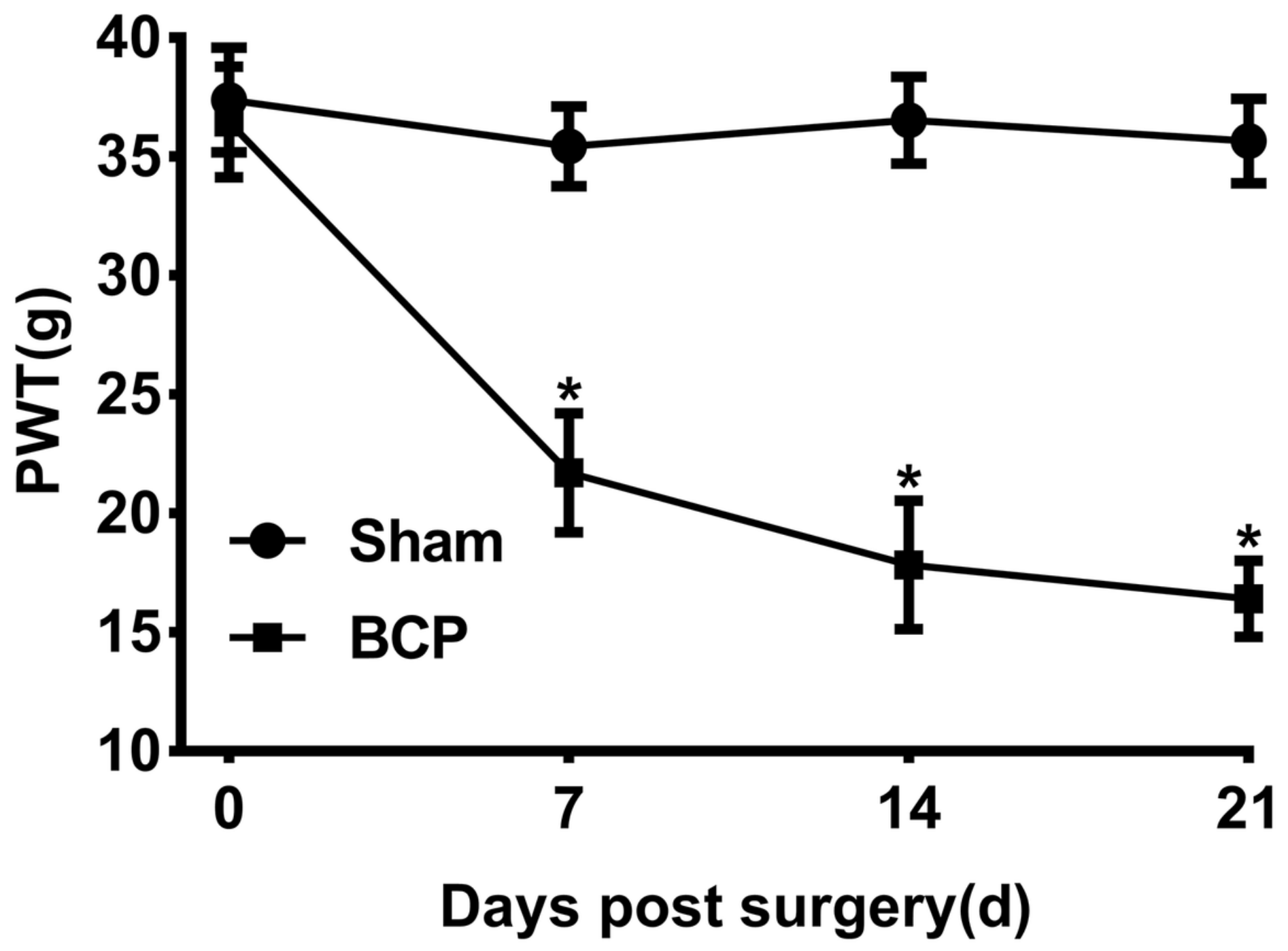

Figure 1

Changes in PWT of the ipsilateral paw in the Sham and BCP groups

Carcinoma implantation significantly decreased the PWT of the ipsilateral paw of the rat on the day 7, 14, and 21 after inoculation, whereas that in the sham group showed no significant change. Values represent as mean \pm SEM, $n=12-14$ for each group. ${ }^{*} p<0.05$ compared with the sham group. BCP: bone cancer pain; PWT: paw withdrawal threshold. 


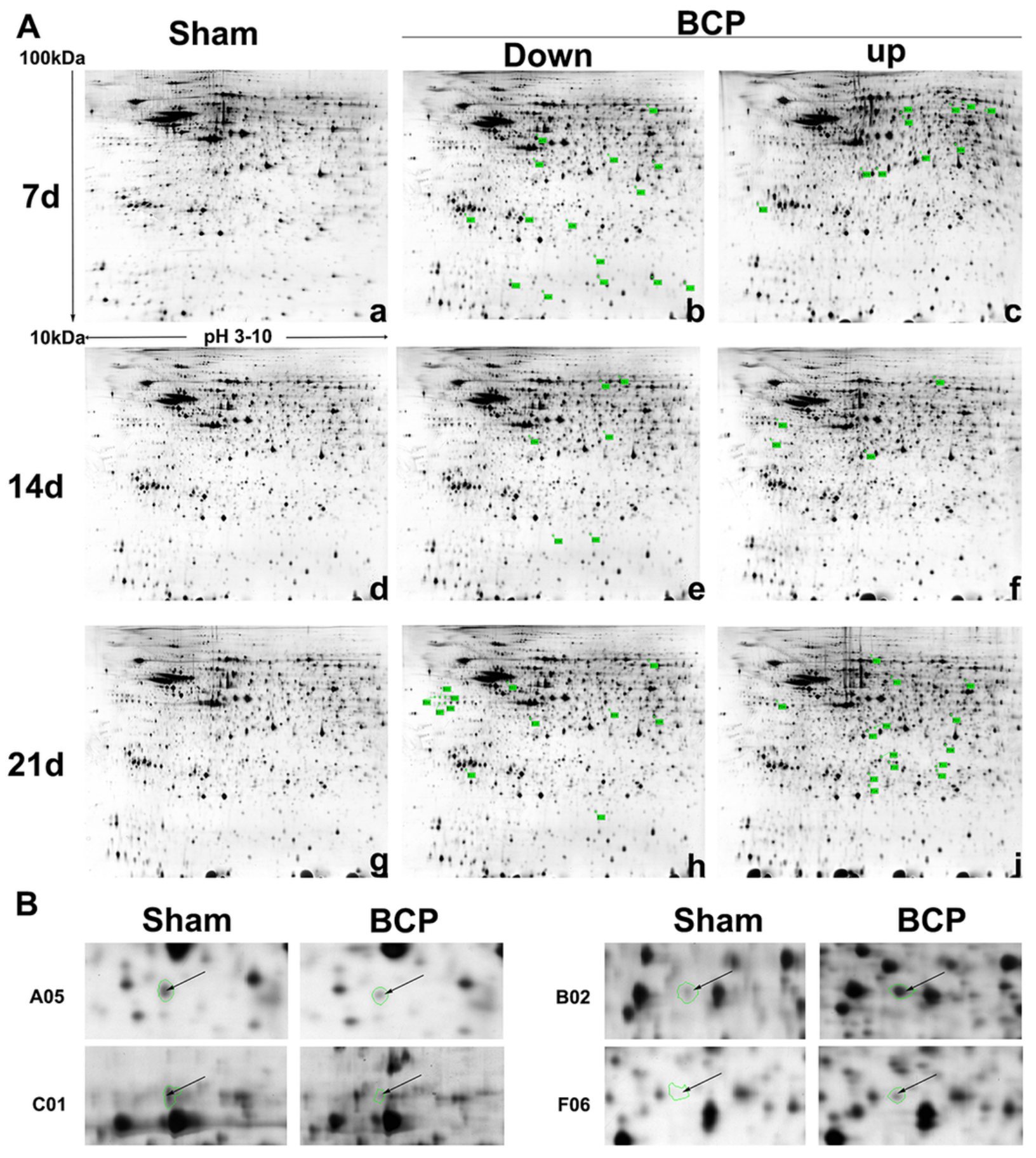

Figure 2

2-DE gel images of rat lumbar spinal cord samples and the corresponding differentially expressed protein spots

Using a pH 3-10, $17 \mathrm{~cm}$ nonlinear JPG strip and 12.5\% SDS-PAGE, we identified 60 DEPs on the gels. (A) 2-DE map of rat lumbar spinal cord samples of the Sham and BCP groups on the day 7, 14, and 21 after inoculation. Fig. 2a, $2 \mathrm{~d}$, and $2 \mathrm{~g}$ were Sham group. Fig. $2 \mathrm{~b}, 2 \mathrm{e}$, and $2 \mathrm{~h}$ are up-regulated in BCP group compared with Sham group. Fig. 2c, $2 f$, and $2 \mathrm{i}$ were down-regulated in the BCP group compared with Sham group. DEPs were labeled in green number. (B) Four representative DEPs circled in green were magnified from two pairs of rat lumbar spinal cord samples. 


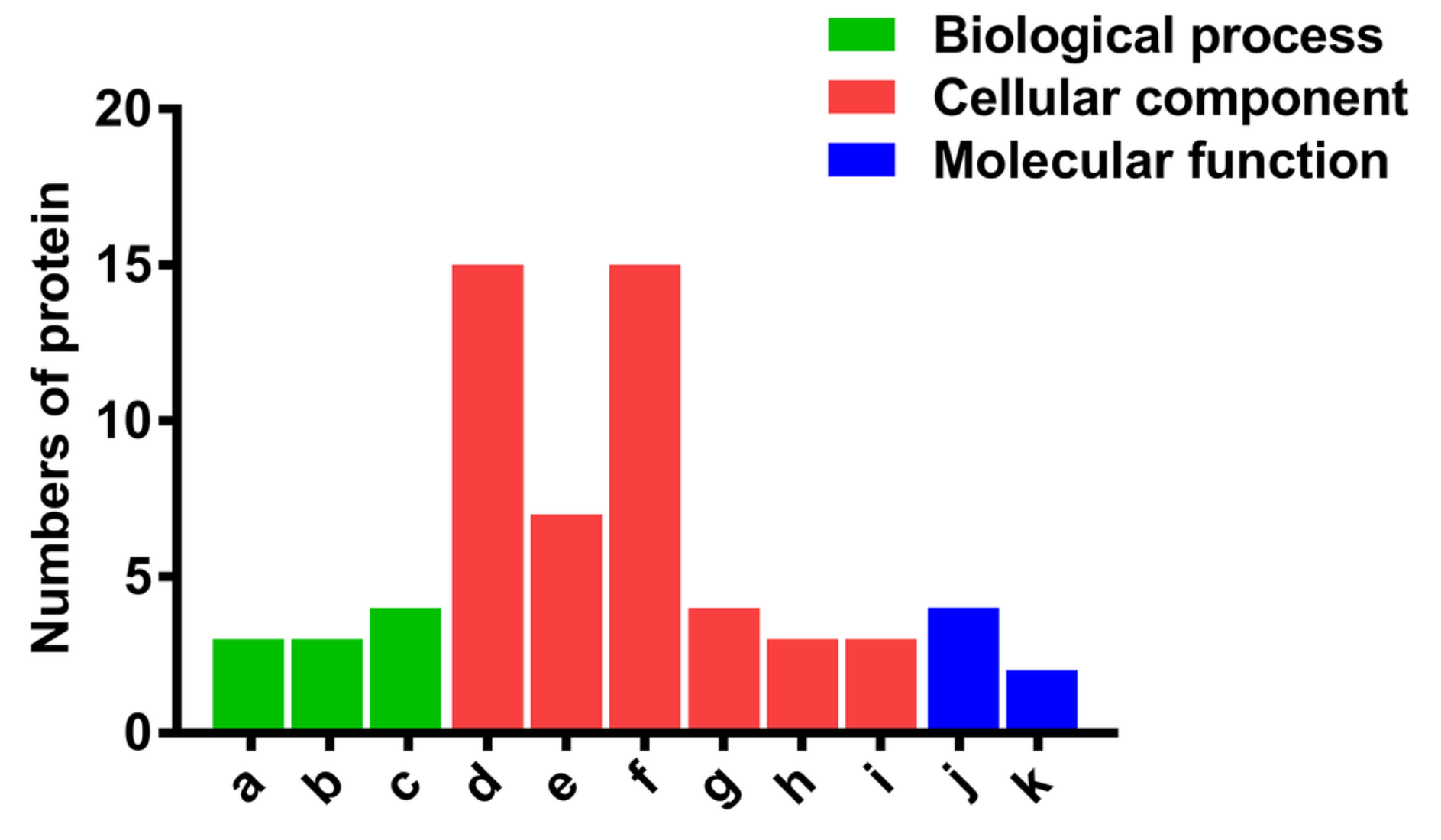

Figure 3

Functional enrichment analysis of DEPs

Gene Ontology (GO) enrichment analysis was performed using DAVID online tool for DEPs according to three main term annotation categories, namely biological process term categories, cellular component category and molecular function category. a: actin filament organization; b: hippocampus development; c: oxidation-reduction process; d: extracellular exosome; e: myelin sheath; f: cytoplasm; j: neuron projection; h: growth cone; i: cytoskeleton; j: actin binding; $k$ : toxic substance binding. 


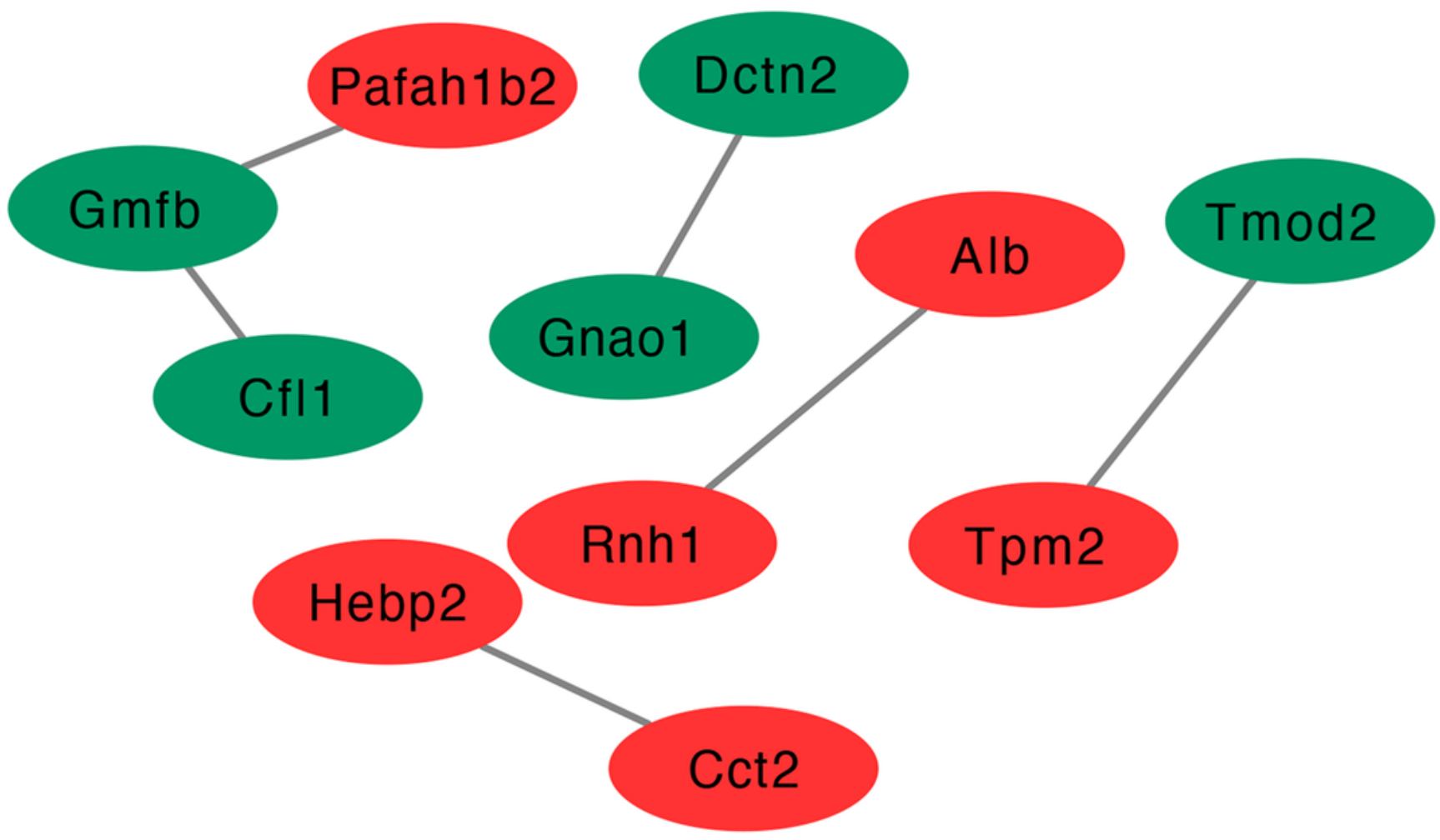

Figure 4

PPI network analysis of DEPs

PPI networks were analyzed using STRING public database information and visualized using Cytoscape. The nodes represent proteins, and the edges represent pair-wise interaction. Upregulated proteins are marked in red; Downregulated proteins are marked in green. 